\title{
Endogenous Glucagon-Like Peptide-1 as a Potential Mediator of the Resolution of Diabetic Kidney Disease following Roux en Y Gastric Bypass: Evidence and Perspectives
}

\author{
Neil G. Docherty ${ }^{1}$ and Carel W. Le Roux ${ }^{1,2,3}$ \\ ${ }^{1}$ Diabetes Complications Research Centre, Conway Institute of Biomolecular and Biomedical Research, \\ School of Medicine and Medical Sciences, University College Dublin, Belfield, Dublin 4, Ireland \\ ${ }^{2}$ Gastrosurgical Laboratory, University of Gothenburg, Sweden \\ ${ }^{3}$ Investigative Science, Imperial College London, UK \\ Correspondence should be addressed to Neil G. Docherty; neil.docherty@ucd.ie
}

Received 27 April 2014; Revised 1 August 2014; Accepted 25 August 2014; Published 18 September 2014

Academic Editor: James M. Lenhard

Copyright $\odot 2014$ N. G. Docherty and C. W. Le Roux. This is an open access article distributed under the Creative Commons Attribution License, which permits unrestricted use, distribution, and reproduction in any medium, provided the original work is properly cited.

Diabetic kidney disease in patients with type 2 diabetes strongly correlates with the incidence of major cardiovascular events and all-cause mortality. Pharmacological and lifestyle based management focusing on glycaemic, lipid, and blood pressure control is the mainstay of treatment but efficacy remains limited. Roux en Y gastric bypass is an efficacious intervention in diabetes. Emerging evidence also supports a role for bypass as an intervention for early diabetic kidney disease. This paper firstly presents level 1 evidence of the effects of bypass on hyperglycaemia and hypertension and then summarises emerging data on its effects on diabetic kidney disease. Glucagon-like peptide-1 is implicated as a central mediator of diabetes resolution following bypass through the incretin effect. It has been ascribed vasodilatory, pronatriuretic, and antioxidant properties and its exogenous administration or optimisation of its endogenous levels via dipeptidyl peptidase IV inhibition results in antioxidant and antiproteinuric effects in preclinical models of DKD. Some evidence is emerging of translation of coherent effects in the clinical setting. These findings raise the question of whether pharmacotherapy targeted at optimising circulating hormone levels may be capable of recapitulating some of the effects of bypass surgery on renal injury.

\section{Diabetic Kidney Disease: Prevalence, Pathogenesis, and Treatment Options}

Type 2 diabetes (T2DM) and the consequences of its attendant complications are now a worldwide problem. World Health Organisation endorsed findings published in 2011 by the Global Burden of Metabolic Risk Factors of Chronic Diseases Collaborating Group (Blood Glucose) revealed sexspecific prevalence rates of $9.8 \%$ and $9.2 \%$ for males and females, respectively. In high income regions, large increases in fasting plasma glucose levels were associated with increases in body mass index (BMI) attributable to overweight and obesity. Although $80 \%$ of individuals categorised as obese do not develop comorbid T2DM, up to $20 \%$ do and hence it may be the increased disease burden of "diabesity" in these individuals that is fuelling the global epidemic of diabetes.

Subsequent chronic complications of T2DM, particularly diabetic kidney disease (DKD), increase morbidity, mortality [1], and healthcare costs [2]. More than $40 \%$ of patients with diabesity develop DKD. While nonprogressors and the increased risk of fatal cardiovascular events in patients with mild to moderate chronic kidney disease (CKD) restrict the absolute numbers progressing to end-stage renal disease (ESRD), $30 \%$ of patients with DKD do progress to the point where renal replacement therapy becomes necessary $[3,4]$. Therefore, overall, the presence of DKD in patients with T2DM is associated with a poor prognosis irrespective of whether disease progresses to end-stage. Analysis of data 
from the Third National Health and Nutrition Examination Survey (NHANES III) in the United States of America demonstrates that for patients with T2DM without DKD there is a $44 \%$ increase in mortality rate versus individuals drawn from a nondiabetic reference sampling frame [1]. This is however dwarfed by a $400 \%$ increase observed in patients with T2DM and DKD.

Hyperglycaemia can be cited as the core risk factor involved in DKD progression via a number of pathogenic mechanisms while hypertension and dyslipidemia add to the hyperglycaemic insult to drive progression of DKD [5]. In progressive disease an accelerated rate of GFR decline is observed with an annual rate of loss of more than 3 and up to $10 \mathrm{~mL} / \mathrm{min} / 1.73 \mathrm{~m}^{2}$ being typical [1]. Decline in renal function may proceed silently prior to the establishment of frank albuminuria; however decline to the point of renal insufficiency is not generally reached without prior establishment of microalbuminuria.

Optimally, treatment approaches in DKD should target all risk factors with glycaemic control at the centre. The United Kingdom Prospective Diabetes Study (UKPDS) proved that early intensive glycaemic control reduced the risk of developing microvascular complications including DKD in patients with T2DM in the medium [6] and long-term [7].

A number of controlled studies demonstrate that pharmacological control of hypertension via blockade of the renin-angiotensin system (RAS) reduces the incidence of albuminuria in at-risk hypertensive patients with T2DM [8]. For example, evidence from the ADVANCE study indicates that targeting of RAAS activation in combination with diuretic treatment results in a $21 \%$ decrease in appearance or progression of albuminuria and correlates with the magnitude of reduction in systemic blood pressure [9]. Overshooting of antihypertensive effects beyond the target pressures of $130 / 80 \mathrm{mmHg}$ to systolic pressures of as low as $110 \mathrm{mmHg}$ is still associated with renoprotection probably as a consequence of renal autoregulation. The RENAAL study group reported that although treatment with regimens including angiotensin II type 1 receptor blockade yields individual risk reduction treatment effects of $28 \%$ and $25 \%$ on the end-points of doubling of serum creatinine or progression to ESRD over a 3-4-year period, when these end-points are included in a composite outcome along with death, $43.5 \%$ of treated patients reached the end-point illustrating that overall outcomes with usual care pharmacotherapy are still suboptimal [10].

Intensified combination therapy to control all DKD risk factors as in the STENO-2 trial can significantly reduce progression rates in DKD (61\% over 8 years) and mortality [11]. However such favorable outcomes in clinical trials are not easily replicated in practice as a consequence of issues of both compliance and ability to follow up patients dynamically.

\section{Bariatric Surgery and DKD (Table 1)}

Balancing efficacy and safety, RYGB has emerged as the preeminent surgical intervention for obesity and hyperglycemia of T2DM, whilst also providing long-term weight independent benefits on lipid and cardiovascular control which contribute to a marked mortality benefit compared to the best medical care [12-15].

RYGB and other bariatric surgical procedures have been shown to improve renal function, rates of albuminuria, and evidence of renal inflammation in a number of studies as recently reviewed by our group [16].

To date, the most compelling prospective study published regarding the effect of bariatric surgery versus conventional medical therapy on DKD is an unblinded, case-controlled trial by Iaconelli et al. [17] examining the effects of biliopancreatic diversion (BPD) on urinary albumin excretion and GFR in 50 patients with obesity and newly diagnosed T2DM. At 10-year follow-up there was a $45 \%$ delta reduction in GFR in patients in the conventional arm versus a $13.6 \%$ increase in GFR in the surgical group. All subjects in the BPD group improved and then recovered from microalbuminuria, whereas in the control group albuminuria was uniformly worsened over the time period.

Navarro-Díaz et al. [18] prospectively studied 61 adults with BMIs of greater than $40 \mathrm{~kg} / \mathrm{m}^{2}$ before and over a 24 month period after RYGB surgery. GFR, 24-hour proteinuria, and 24-hour albuminuria improved within the first year and a sustained improvement in albuminuria was observed over 2 years that tracked to improvements in BMI.

Amor et al. [19] studied 96 patients with T2DM undergoing RYGB or vertical sleeve gastrectomy (VSG) with a focus on describing the impact of surgery and associated weight loss on urinary albumin excretion. At baseline, albumin creatinine ratios (ACRs) of greater than $30 \mathrm{mg} / \mathrm{g}$ (microalbuminuria) were present in $45.7 \%$ of participants. In these patients $58.5 \%$ and $76.9 \%$ had reverted to ACRs below the threshold for microalbuminuria at 12 and 24 months, respectively. This was predicated upon a steep fall-off in ACRs over the first year, which led to a significant decrease in means ACRs for the cohort from $85.7 \pm 171 \mathrm{mg} / \mathrm{g}$ at baseline to $42.2 \pm 142.8 \mathrm{mg} / \mathrm{g}$ at 12 months.

Fenske et al. [20] prospectively evaluated bodyweight, blood pressure, and urinary and serum cytokines at baseline and at 1 and 12 months in 30 morbidly obese patients following laparoscopic adjustable gastric banding (LAGB) $(n=13)$, RYGB $(n=10)$, and VSG $(n=11)$. Reduced urinary and serum levels of macrophage inhibitory factor, monocyte chemotactic protein-1, and chemokine ligand 18 were observed at follow-up and in 9 patients with a baseline serum cystatin $\mathrm{C}>0.8 \mathrm{mg} / \mathrm{L}$; significant improvements were observed after 12 months.

Johnson et al. [21] conducted a large 13-year retrospective analysis of microvascular outcomes in 2580 patients undergoing bariatric surgery and 13,371 nonoperated controls meeting the same inclusion criteria. Surgery was associated with a significant reduction in microvascular events including endstage renal disease (ESRD) (adjusted HR 0.22, 95\% CI 0.09 to 0.49).

Miras et al. [22] carried out a retrospective analysis of 84 consecutive patients with T2DM that had undergone bariatric surgery over a 12-18-month period. In a subset of 32 patients undergoing RYGB who had preoperative 
TABLE 1: Summary of studies reporting on the effect of bariatric surgery on diabetic kidney disease.

\begin{tabular}{|c|c|c|c|c|c|}
\hline Study type & Citation & Intervention & $n$ & Follow-up & Effect on DKD \\
\hline \multirow{4}{*}{ Prospective } & Iaconelli et al. [17] & $\begin{array}{l}\text { BPD versus usual } \\
\text { care } \\
\text { (case-control) }\end{array}$ & 50 & 10 years & $\begin{array}{l}\text { Improved GFR and improvement and remission } \\
\text { of albuminuria }\end{array}$ \\
\hline & Navarro-Díaz et al. [18] & $\begin{array}{l}\text { RYGB against } \\
\text { healthy controls }\end{array}$ & 61 & 2 years & Reduction and remission of albuminuria \\
\hline & Amor et al. [19] & $\begin{array}{l}\text { RYGB and VSG } \\
\text { (observational) }\end{array}$ & 96 & 12 months & Reduction and remission of albuminuria \\
\hline & Fenske et al. [20] & $\begin{array}{l}\text { RYGB, LAGB, and } \\
\text { VSG } \\
\text { (observational) }\end{array}$ & 30 & 12 months & $\begin{array}{l}\text { Improved renal inflammation and reduced serum } \\
\text { cystatin C }\end{array}$ \\
\hline \multirow{8}{*}{ Retrospective } & Brethauer et al. [12] & $\begin{array}{l}\text { RYGB, VSG, and } \\
\text { LAGB }\end{array}$ & 217 & 5 years & Regression of diabetic nephropathy \\
\hline & Miras et al. [22] & $\begin{array}{l}\text { RYGB, VSG, and } \\
\text { LAGB }\end{array}$ & 84 & $\begin{array}{l}12-18 \\
\text { months }\end{array}$ & Reduction in mean urinary ACRs \\
\hline & Johnson et al. [21] & Not specified & 15,951 & $>13$ years & Reduction in microvascular composite \\
\hline & Heneghan et al. [23] & $\begin{array}{l}\text { RYGB, VSG, and } \\
\text { LAGB }\end{array}$ & 52 & 5 years & $\begin{array}{l}\text { Reduction, prevention, and remission of } \\
\text { albuminuria }\end{array}$ \\
\hline & Carlsson et al. [24] & $\begin{array}{l}\text { RYGB, VBG, and } \\
\text { LAGB }\end{array}$ & 3108 & 15 years & Halving of incidence of albuminuria \\
\hline & Stephenson et al. [25] & LAGB & 23 & 3 years & $\begin{array}{l}\text { Inconsistent picture of albuminuria incidence, } \\
\text { progression, and regression }\end{array}$ \\
\hline & Jose et al. [26] & $\mathrm{BPD}$ & 25 & 4 years & $\begin{array}{l}\text { Reduction in creatinemia and improvement in } \\
\text { eGFR }\end{array}$ \\
\hline & Hou et al. [27] & $\begin{array}{l}\text { RYGB, VSG, and } \\
\text { LAGB }\end{array}$ & 233 & 12 months & $\begin{array}{l}\text { Improvement in eGFR across grades of CKD and } \\
\text { reduction in hyperfiltration }\end{array}$ \\
\hline
\end{tabular}

albuminuria, a mean 3.5-fold decrease in postoperative ACR was recorded.

A 5-year retrospective review by Brethauer et al. [12] showed that in a series of patients with T2DM undergoing bariatric surgery (RYGB- $n=162$, LAGB $n=32$, and VSG $n=23$ ) between 2004 and 2007 DKD regressed in $53 \%$ of patients and stabilised in the remaining $47 \%$.

Heneghan et al. [23] also identified 52 patients with obesity and T2DM at 5-year follow-up following bariatric surgery in whom serial ACR measurements had been made. A total of $37.6 \%$ of patients had DKD preoperatively and this resolved in $58.3 \%$ of those studied at a mean follow-up of 66 months.

Carlsson et al. [24] calculated 15 year incidence rates of albuminuria in 1498 patients that underwent bariatric surgical intervention and 1610 usual care controls. Surgeries included gastric banding (18\%), vertical banded gastroplasty (69\%), and RYGB (13\%). Median follow-up was 10 years, with follow-up rates of $87 \%, 74$, and $52 \%$ at 2,10 , and 15 years, respectively. Albuminuria developed in 246 participants in the control group and 126 of the patients in the bariatric surgery group yielding a hazard ratio of 0.37 ( $95 \%$ confidence interval, 0.30-0.47). A number needed to treat analysis predicted that 4 surgeries in patients with DKD would be required to prevent one case of new onset albuminuria.

Stephenson et al. [25] retrospectively studied 23 patients over 3 years after LAGB to examine effects on albuminuria. Seven patients had macroalbuminuria at baseline, 2 reverted to normoalbuminuria, 2 reverted to microalbuminuria, and 3 remained macroalbuminuric at 36 months of follow-up. Of 16 patients with microalbuminuria at baseline, 9 reverted to normoalbuminuria, 6 showed sustained microalbuminuria, and one progressed to macroalbuminuria.

Jose et al. [26] examined renal function in 25 patients over a mean follow-up of 4 years after BPD. Serum creatinine reduced by $16.2 \pm 19.6 \mu \mathrm{mol} / \mathrm{L}$ and eGFR improved by $10.6 \pm$ $15.5 \mathrm{~mL} / \mathrm{min} / \mathrm{m}^{2}$.

Hou et al. [27] measured changes in GFR in 233 patients at greater than 12 months after bariatric surgery. Sixty-one patients had hyperfiltration at baseline (GFR $\left.146.4 \pm 17.1 \mathrm{~mL} / \mathrm{min} / 1.73 \mathrm{~m}^{2}\right), 127 \mathrm{had}$ a normal GFR $\left(105.7 \pm 9.6 \mathrm{~mL} / \mathrm{min} / 1.73 \mathrm{~m}^{2}\right), 39 \mathrm{had}$ stage 2 CKD $\left(76.8 \pm 16.7 \mathrm{~mL} / \mathrm{min} / 1.73 \mathrm{~m}^{2}\right)$, and 6 had stage 3 CKD $\left(49.5 \pm 6.6 \mathrm{~mL} / \mathrm{min} / 1.73 \mathrm{~m}^{2}\right)$. Mean GFR 1 year after weight loss surgery decreased to $133.9 \pm 25.7 \mathrm{~mL} / \mathrm{min} / 1.73 \mathrm{~m}^{2}$ in the hyperfiltration group, increased to $114.2 \pm 22.2 \mathrm{~mL} / \mathrm{min} / 1.73 \mathrm{~m}^{2}$ in the normal group, increased to $93.3 \pm 20.4 \mathrm{~mL} / \mathrm{min} / 1.73 \mathrm{~m}^{2}$ in the CKD stage 2 group, and increased to $66.8 \pm 19.3 \mathrm{~mL} / \mathrm{min} / 1.73 \mathrm{~m}^{2}$ in the CKD stage 3 group.

Although a promising evidence base is emerging in relation to the effects of bariatric surgery on $\mathrm{DKD}$, results of prospective RCTs designed with CKD as a primary endpoint comparing specific interventions such as RYGB against other surgical and medical modalities have been lacking to date. However a number of them are now registered 
and currently recruiting including two trials comparing the effects of RYGB versus medical and lifestyle management of disease on progression of mild or moderately advanced DKD (see clinicaltrials.gov NCT01974544 and NCT01821508).

Concerns do persist regarding the use of RYGB in patients with CKD. Retrospective analyses of outcomes following complex abdominal surgery (major colorectal, hepatobiliary, pancreatic, gastric, and esophageal operations) in patients with CKD show that preoperative renal function predicts 30-day postoperative morbidity and mortality [28]. Impairment comparable with moderately advanced renal decline in T2DM (GFR, $45-60 \mathrm{~mL} / \mathrm{min} / 1.73 \mathrm{~m}^{2}$ ) is associated with 1.6-fold increase in relative risk of death. RYGB is also associated in some patients with oxalate nephropathy and nephrolithiasis which can precipitate accelerated decline to ESRD [29]. Thus although RYGB may be a good treatment option for patients with DKD, particularly those with only mildly to moderately advanced disease, identification of the physiological mediators of RYGB and their optimal application in pharmacological approaches is a desirable goal for future research efforts.

Having established from the above that bariatric surgery is associated with a reduction in proteinuria in clinical series and given that this is a proxy of reduced renal injury, it is a timely point in the paper to focus specifically on RYGB surgery which may provide for weight independent amelioration of the known risk factors for DKD progression through alterations in gut signalling, a principal component of which may rely on augmented release of incretin hormones.

\section{A Summary of the Metabolic and Cardiovascular Effects of RYGB}

A seminal systematic review and meta-analysis published in 2004 examined 136 studies reporting metabolic and cardiovascular outcomes of bariatric surgery in 16,994 individuals in addition to the standard primary end-point of weight loss [30]. Bariatric surgery (including RYGB) was associated with improvements in diabetes (86\%), lipid control (70\%), hypertension $(78.5 \%)$, and obstructive sleep apnoea (83.6\%). These findings have been followed up in prospective randomised controlled trials using several of the parameters singly and/or in combination as primary and secondary end-points.

\section{Glycaemic Control and the Incretin Effect after RYGB}

Resolution of T2DM following bariatric surgery was an initially serendipitous discovery [31]. Level 1 evidence from prospective randomised controlled trials (RCTs) has subsequently corroborated this finding by clearly demonstrating the efficacy of RYGB as an intervention for glycaemic control in T2DM. A prospective study of 60 patients with T2DM of 5 years or more of duration revealed a 2 -year rate of diabetes remission following RYGB of $75 \%$ (defined as plasma glucose $<5.6 \mathrm{mM}$ and glycated haemoglobin Alc (HbAlc) $<6.5 \%(47.5 \mathrm{mmol} / \mathrm{mol})$ ) [32]. No patients followed up by usual care achieved the primary end-point. When medical care is intensified, prospective RCT based head-to-head comparisons at 12 months show that using a more stringent end-point of $\mathrm{HbAlc}$ of $6 \%(42.1 \mathrm{mmol} / \mathrm{mol})$ results in $12 \%$ of patients receiving intensified medical therapy achieving the primary end-point criterion versus $42 \%$ of RYGB patients [33]. Analysis of 3-year data comparing RYGB versus intensive medical therapy on the same end-point demonstrates that $38 \%$ of RYGB patients achieve an HbAlc below $6 \%$ $(42.1 \mathrm{mmol} / \mathrm{mol})$ versus $5 \%$ of patients followed by intensive medical therapy [34]. Longitudinal follow-up of the Swedish Obese Subjects (SOS) case-control study also demonstrates that incidence of diabetes at 15-year follow-up is markedly reduced by bariatric surgery, particularly RYGB (hazard ratio versus usual care 0.17) [35] but that most patients who initially go into remission eventually relapse, albeit having had much improved glycaemic control for years or decades.

RYGB leads to long-term bodyweight loss maintenance in the region of $25-30 \%$ and is associated with improvements in peripheral insulin resistance which sustain longterm glycaemic control. Notably however very early gains in glycaemic control are observed which precede significant weight loss. Immediate improvements in glycaemic control may be based on the effects of food restriction on hepatic insulin resistance but importantly have been shown to rely on characteristic increases in the first phase insulin secretion in response to feeding, reflecting the exaggerated postprandial release of "incretin" gut hormones such as GLP-1 that act to increase $\beta$-cell glucose sensitivity in the short-term and in rodent studies support preservation of functional islets in the longer-term $[36,37]$.

\section{Blood Pressure Control following RYGB}

The pathogenesis of DKD in diabesity is exacerbated by obesity related hypertension which is characterised by antinatriuretic signalling arising as a consequence of elevated sympathetic tone, consequent activation of the RAS pathway, and physical compression of the kidneys [38]. Direct repercussions of systemic hypertension in relation to DKD include promotion of hyperfiltration and albuminuria and direct effects on renal remodelling, with hyaline arteriosclerosis likely a direct reflection of hypertension.

RYGB is superior versus several intensified lifestyle modification approaches and other bariatric surgical procedures in achieving blood pressure targets and sustaining them in the long-term [39]. This is attributable on multifactorial analysis to weight loss over the first year [40, 41]. Comparing RYGB with the best medical care plus or minus exenatide (GLP1 receptor agonist) shows a significant reduction from 2.8 to 0.5 in the mean number of antihypertensive medications required after 12 months [42]. In this study an intermediate effect was observed when exenatide was added to usual care suggesting a direct antihypertensive effect of GLP-1 agonists. The multicentre diabetes surgery randomised trial measured achievement of a composite of glycaemia (HbAlc $<7 \%$ ), LDL cholesterol $(<100 \mathrm{mg} / \mathrm{dL})$, and systolic blood pressure $(<130 \mathrm{mmHg})$ at 1 year [43]. This was met in $49 \%$ of the RYGB group versus $11 \%$ in the medical and lifestyle group and was 
associated with a significant reduction in requirements for antihypertensive medications. Regression analysis attributed this mainly to weight loss. The period of the steepest decline in blood pressure in the diabetes surgery study also occurs early within the first 3 months after surgery [43].

Blood pressure changes have however been recorded at early time-points after RYGB concurrent with the chronology of the incretin effect and before substantial weight loss has occurred. Blood pressure measured longitudinally in 100 patients before and at $1,5,9,26$, and 52 weeks after RYGB [44] showed that reductions of up to $9 \mathrm{mmHg}$ were observed as early as 1 week postoperatively which were sustained along with a $66 \%$ reduction in requirement for antihypertensive medication. Elsewhere retrospective analysis of data on systolic and diastolic blood pressure in 95 patients before and at 1 week, 1 month, and 3, 6, 9, and 12 months after RYGB demonstrated up to $20 \mathrm{mmHg}$ reductions in systolic pressure by 1 year after RYGB with the period of the steepest decline (85\% of total reduction) occurring during the first postoperative month [45].

Evidence therefore suggests that RYGB is associated with a benefit in relation to blood pressure control which may be reflective in the long-term of weight loss but may be underpinned by an early and sustained physiological signal which temporally correlates with that observed for the incretin effect on glycaemic control. This may be suggestive of redundancy in relation to the mediators of diverse early responses to RYGB, implying, for example, that improvements in glycaemic control may not be the only effect of gut hormones such as GLP-1.

\section{GLP-1}

Glucagon-like peptide-1 (GLP-1) is a 30-amino-acid peptide hormone derived from posttranslational processing of the proglucagon precursor molecule. GLP-1 is released from enteroendocrine L-cells in response to nutrient and is typically implicated as a mediator of the antidiabetic effects of RYGB via afferent vagal and endocrine driven incretin effects arising through increasing $\beta$-cell glucose sensitivity in the short-term and support of islet structure and function in the long-term via $G_{s}$ coupled receptor and cyclic AMP dependent pathways $[24,46]$. The antidiabetic actions of GLP-1 also rely on both insulin dependent and insulin independent reductions in glucagon secretion and delayed gastric emptying [24].

The direct endocrine actions of native GLP-1 are normally restricted as a consequence of enzymatic cleavage by membrane-bound dipeptidyl-peptidase-IV (DPP-IV) found on the luminal aspect of the endothelium of draining intestinal capillaries. This necessarily restricts effective circulating levels of GLP-1. Multiple means of circumventing GLP-1 inactivation to optimise endocrine effects have been developed and licensed for use as antidiabetic agents (GLP-1 receptor agonists (exendin, exenatide), DPP-IV inhibitors (gliptins), and stable GLP-1 analogues (liraglutide)) [46]. Liraglutide is a stable fatty acid conjugate of native GLP-1 incorporating a single conservative amino-acid change resulting in a molecule active at the GLP-1 receptor but with a prolonged plasma half-life due to albumin binding. Liraglutide is one of the most widely used agents in T2DM treatment algorithms with meta-analysis of large trials [47] showing it to be an efficacious means of normalising fasting glycaemia and more especially postprandial glucose excursions in T2DM to allow for the achievement of long-term target reductions in HbAlc. Liraglutide is of particular relevance to the treatment of T2DM in diabesity and drawing parallels between the effects of surgery and exogenous GLP-1 provision given its emerging effects on weight loss and hypertension in prospective RCTs [48-51].

\section{GLP-1 and Glycaemic Control after RYGB}

Support for a causative role for GLP-1 in glycaemic control dependent on preservation of endocrine pancreatic function following RYGB is forthcoming from numerous studies. Three recent observations when considered together strongly support the long-standing implication of GLP-1 as an important mediator of improved glycaemic control after RYGB: (1) crossover examination of the effect of GLP-1 antagonism (exendins 9-39) before and 1 week and 3 months after surgery shows that improved glucose tolerance and $\beta$-cell glucose sensitivity in response to a test meal are reversed suggesting that GLP-1 action has played a long-term component role in improvements [52]; (2) at 5 years after RYGB, infusion of exendins 9-39 increased glucose excursion and decreased insulin secretion in response to a test meal [52]; and (3) postprandial increases in GLP-1 levels remain elevated over time after RYGB but do not independently predict postprandial glycaemic control [53]. These findings imply that GLP1 mediates improved glycaemic control after RYGB at least in part through enhanced insulin secretion, a phenomenon that depends on retention of a certain measure of $\beta$-cell reserve. Hence the benefits of GLP-1 are tied to preservation of endocrine pancreatic function.

\section{GLP-1 Induced Natriuresis as a Potential Mediator of the Antihypertensive Effects of RYGB}

Secondary analysis of data from the SOS study demonstrates that 10 years after surgery improved relative reductions in blood pressure $(3.6 \mathrm{mmHg}$ (systolic) and $3.5 \mathrm{mmHg}$ (diastolic)) occur following RYGB but not gastric banding or vertical banded gastroplasties, the latter of which are not associated with exaggerated postprandial GLP-1 release [14, 39, 54]. The "Longitudinal Assessment of Bariatric Surgery" consortium also reports dissociation in 3-year rates of remission of hypertension between RYGB (38.2\%) and gastric banding (17.4\%) [55]. The RYGB specific effects in SOS were associated with a $170 \mathrm{~mL}$ increase in 24-hour diuresis and a $20 \mathrm{mmol}$ increase in 24-hour urinary sodium excretion [39]. As enhanced postprandial GLP-1 release occurs very early after RYGB surgery and is sustained in the long-term but this does not occur after restrictive procedures, it follows that, given the known natriuretic effects of GLP-1, it may be 
a mediator of the differences between RYGB and restrictive bariatric procedures in relation to blood pressure control. Providing mechanistic support for these findings, we have also demonstrated in a rat model of RYGB that hyperosmolar oral sodium challenge evokes a $33 \%$ increase in urinary output and a doubling of sodium excretion over 8 hours [56].

Postprandial GLP-1 responses are increased following RYGB and maintained over the longer-term [57] while infusion of GLP-1 in healthy volunteers over 3 hours doubles urinary sodium excretion [58] and is associated with a reduction in urinary $\mathrm{H}^{+}$excretion implying a role for the inhibition of the proximal tubular sodium-hydrogen antiporter 3 (NHE3) in this effect. Ex vivo tubular micropuncture and gene expression/activity studies in rats support this hypothesis [59]. This response is sustained in a mouse model of diabesity in response to exendin-4 administration [60]. Recent findings identify GLP-1 receptors on the afferent arteriole of the glomerulus [61] consistent with an effect of GLP-1 not only on tubular function but also on renal haemodynamics which in combination elevate GFR but reduce tubular reabsorption resulting in diuresis and natriuresis [62].

A gut-heart-kidney natriuretic axis involving GLP-1 mediated stimulation of natriuretic peptide release and subsequent cyclic GMP (cGMP) dependent induction of natriuresis has recently been elucidated in mice and may explain some of the antihypertensive effects of GLP-1 action after RYGB and of pharmacological manipulation of GLP1 levels [63]. This may be mediated via elevations in GFR and inhibition of the epithelial sodium channel $(\mathrm{ENaC})$ in the distal nephron. Although elevations in circulating B-type natriuretic peptide are usually indicative of volume overload, RYGB is associated with rapid and sustained increases in BNP of $125 \%$, a phenomenon not observed following diet induced weight loss. This may provide a clue to the indirect mediation of natriuresis induced by elevated GLP-1 following RYGB [64].

The pronatriuretic mechanisms described above may directly and indirectly (via natriuretic peptide mediated inhibition of aldosterone release) antagonise the activation and downstream antinatriuretic effects of the systemic RAS, potentially offering a further part explanation for the reduced requirement for antihypertensive medications after RYGB. Additionally both endogenous hyperinsulinaemia and administration of exogenous insulin are associated with a pressor response based on increased renal sodium reclamation through direct effects on renal sodium transporter expression and activity (e.g., NHE3) [65]. Hence reductions in insulin requirements after RYGB or in the presence of GLP-1 agonists as part of combination medical therapy could provide an antihypertensive signal mediated through the promotion of natriuresis. Improved glycaemic control and reduced exogenous insulin requirements may also in turn act to limit systemic RAS activation by reducing proximal tubular sodium reclamation via sodium glucose cotransporters 1 and 2 (SGLT1 and SGLT2). This in turn could prevent inappropriate distal tubular sensing of a sodium deficit in the context of hyperglycaemia which has been linked to hyperfiltration and the increased release of renin (hence systemic RAS activation and a pressor response).

\section{The Effect of Pharmacological Optimisation of GLP-1 Levels on DKD: Preclinical Evidence (Table 2)}

The preceding paragraphs outline the evidence and rationale for implicating GLP-1 activity as a mediator of improvements in DKD relevant risk factor reduction in terms of glycaemic and blood pressure control after RYGB and raise the question of whether inclusion of pharmacological manipulation of GLP-1 levels in the medical management of T2DM might be of significant benefit in relation to reducing the progression of DKD.

The rationale for trials in humans examining renal endpoints in response to GLP-1 based pharmacotherapy is premised upon a body of evidence collected in preclinical rodent models of experimental DKD which have examined the impact of treatment with GLP-1 analogues and agonists and DPP-IV inhibitors (Table 2).

Liraglutide has been demonstrated to reduce albuminuria and renal structural changes in lean models of primary endocrine pancreatic destruction in rats and mice $[66,67]$ with evidence supportive of an important role for adenylate cyclase dependent inhibition of oxidative stress [66].

The GLP-1 receptor agonist, exendin-4, has been shown to reduce albuminuria and associated indices of renal injury, inflammation, and oxidative stress in streptozotocin (STZ) induced diabetes $[68,69]$ and in the leptin receptor null $d b / d b$ mouse model of diabesity [70].

Treatment with the DPP-IV inhibitor PKF275-055 and sitagliptin has also been shown to reduce proteinuria and preserve renal structure and function (creatinine clearance) in STZ rat models [71, 72]. Alter et al. have shown that linagliptin reduces albuminuria and glomerulosclerosis when used in combination with an angiotensin receptor blocker in endothelial nitric oxide synthase knockout mice treated with STZ [73]. Both the cryptic egg protein derived DPPIV inhibitor NWT-03 and sitagliptin reduce albuminuria and improve measures of glomerulosclerosis, renal inflammation, and uraemia up to 6 months of age in the ZDF rat model of diabesity $[74,75]$.

\section{The Effect of Pharmacological Optimisation of GLP-1 Levels on DKD: Supportive Clinical Evidence}

To date there is a scarcity of firm and extensive evidence base suggestive of the fact that the renoprotective effects of GLP-1 observed in preclinical studies are translatable to the clinical setting.

Kawasaki et al. [76] administered sitagliptin at $50 \mathrm{mg}$ /day to 247 patients with T2DM type 2 diabetes for 3 months after which there was significant difference in mean urinary albumin excretion. However when post hoc analysis was focused on those patients with albuminuria at baseline significant reductions in urinary albumin excretion were observed that were independently associated with the magnitude of reductions in systolic blood pressure, suggesting that there may be a potential link between the antihypertensive 
TABLE 2: Summary of the effect of GLP-1 based therapy on renal injury in preclinical models of diabetes.

\begin{tabular}{|c|c|c|c|c|}
\hline Drug class & Drug & Citation & Model & Summary of key findings \\
\hline \multirow{2}{*}{ GLP-1 analogue } & Liraglutide & $\begin{array}{l}\text { Fujita et al., } 2014 \\
{[66]}\end{array}$ & $\begin{array}{l}\mathrm{STZ} \text { in male rats } \pm 0.6 \mathrm{mg} / \mathrm{kg} / \mathrm{day} \text { for } 4 \\
\text { weeks }\end{array}$ & $\begin{array}{l}\text { Inhibition of albuminuria in } \\
\text { combination with reduced oxidative } \\
\text { stress and fibrosis }\end{array}$ \\
\hline & Liraglutide & $\begin{array}{l}\text { Ojima et al., } 2013 \\
{[68]}\end{array}$ & $\begin{array}{l}\mathrm{KK} / \mathrm{Ta} \text { Akita male mice, } 200 \mathrm{ug} / \mathrm{kg} / \text { day } \\
\text { for } 4 \text { weeks from } 8 \text { to } 12 \text { weeks }\end{array}$ & $\begin{array}{l}\text { Adenylate cyclase dependent decrease } \\
\text { in albuminuria, histopathological } \\
\text { changes, and oxidative stress }\end{array}$ \\
\hline \multirow{3}{*}{$\begin{array}{l}\text { GLP-1 receptor } \\
\text { agonists }\end{array}$} & Exendin-4 & $\begin{array}{l}\text { Kodera et al., } 2011 \\
{[69]}\end{array}$ & $\begin{array}{l}\text { STZ in male rats } \pm \text { continuous } \\
\text { infusion of } 0.5 \mathrm{ug} / \mathrm{kg} \text { for } 2 \text { weeks }\end{array}$ & $\begin{array}{l}\text { Inhibition of albuminuria in } \\
\text { combination with reduced oxidative } \\
\text { stress and histopathological changes }\end{array}$ \\
\hline & Exendin-4 & $\begin{array}{l}\text { Park et al., } 2007 \\
{[70]}\end{array}$ & $\begin{array}{l}\mathrm{STZ} \text { in male rats } \pm 10 \mathrm{ug} / \mathrm{kg} / \text { day for } 4 \\
\text { weeks }\end{array}$ & $\begin{array}{l}\text { Reduced albuminuria and } \\
\text { hyperfiltration in association with } \\
\text { reduced histopathological change and } \\
\text { attenuated inflammation, oxidative } \\
\text { stress, and fibrosis }\end{array}$ \\
\hline & Exendin-4 & Liu et al., 2012 [71] & $\begin{array}{l}d b / d b \text { male mice } \pm 0.5 \text { or } \\
1 \mathrm{nmol} / \mathrm{kg} / \text { day for } 8 \text { weeks from } 8 \text { to } 16 \\
\text { weeks }\end{array}$ & $\begin{array}{l}\text { Reduced albuminuria in association } \\
\text { with attenuated histopathological } \\
\text { change, inflammation, and oxidative } \\
\text { stress }\end{array}$ \\
\hline \multirow{5}{*}{$\begin{array}{l}\text { DPP-IV } \\
\text { inhibitors }\end{array}$} & PKF-275-055 & $\begin{array}{l}\text { Alter et al., } 2012 \\
\text { [73] }\end{array}$ & $\begin{array}{l}\mathrm{STZ} \text { in male rats } \pm 4 \mathrm{mg} / \mathrm{kg} / \text { day for } 8 \\
\text { weeks }\end{array}$ & $\begin{array}{l}\text { Reduced albuminuria in association } \\
\text { with improved histopathology and } \\
\text { evidence of anti-inflammatory effect }\end{array}$ \\
\hline & $\begin{array}{l}\text { NWT-03 egg } \\
\text { protein } \\
\text { hydrolysate }\end{array}$ & $\begin{array}{l}\text { Mega et al., } 2011 \\
{[74]}\end{array}$ & $\begin{array}{l}\text { Male ZDF rats } \pm 1 \mathrm{~g} / \mathrm{kg} / \mathrm{day} \text { for } 15 \\
\text { weeks from } 10 \text { to } 25 \text { weeks }\end{array}$ & $\begin{array}{l}\text { Reduced albuminuria, oxidative stress, } \\
\text { and glomerulosclerosis }\end{array}$ \\
\hline & Sitagliptin & $\begin{array}{l}\text { Kawasaki et al., } \\
2014[76]\end{array}$ & $\begin{array}{l}\text { Male ZDF rats } \pm 10 \mathrm{mg} / \mathrm{kg} / \text { day for } 6 \\
\text { weeks from } 20 \text { to } 26 \text { weeks }\end{array}$ & $\begin{array}{l}\text { Reduced uraemia and } \\
\text { glomerulosclerosis }\end{array}$ \\
\hline & Vildagliptin & $\begin{array}{l}\text { Kodera et al., } 2014 \\
{[72]}\end{array}$ & $\begin{array}{l}\mathrm{STZ} \text { in male rats } \pm 4 \text { or } 8 \mathrm{mg} / \mathrm{kg} / \text { day } \\
\text { for } 24 \text { weeks }\end{array}$ & $\begin{array}{l}\text { Reduced albuminuria, improved } \\
\text { creatinine clearance, and less evidence } \\
\text { of glomerular and interstitial fibrosis }\end{array}$ \\
\hline & Linagliptin & $\begin{array}{l}\text { Wang et al., } 2012 \\
{[75]}\end{array}$ & $\begin{array}{l}\text { STZ in male eNOS KO mice } \pm \\
3 \mathrm{mg} / \mathrm{kg} / \text { day for } 12 \text { weeks }\end{array}$ & $\begin{array}{l}\text { Reduced albuminuria and } \\
\text { glomerulosclerosis when in } \\
\text { combination with an angiotensin } \\
\text { receptor blocker }\end{array}$ \\
\hline
\end{tabular}

effects of GLP-1 and improvements in renal injury. A pooled analysis of four studies including a total of 217 patients with T2DM and albuminuria in receipt of RAS blockade pharmacotherapy at baseline demonstrated that addition of linagliptin ( $3: 1$ active versus placebo) at $5 \mathrm{mg} /$ day resulted in a $32 \%$ reduction in albumin excretion rates at 6 months versus only $6 \%$ in the placebo group [77]. In this case delta change in blood pressure was not found to be associated with response which brings into question the proposed natriuretic effects of GLP-1 as a mediator of blood pressure control although the stable treatment with RAS blockade in the cohort studied could mask the antihypertensive effect or leave only the cytoprotective antioxidant effects of GLP-1 emphasised. Alternatively renoprotective effects of gliptins may be mediated by inhibition of the effects of gliptins on DPP-IV targets other than GLP-1. In a single series of 23 patients with DKD treated for 12 months with $0.9 \mathrm{mg} / \mathrm{day}$ of liraglutide significant decreases in proteinuria and a reduction in estimated GFR (eGFR) decline were noted [78].
Evidence demonstrating that 16-week treatment of a group of patients with T2DM and albuminuria with exenatide leads to marked reductions in urinary collagen IV and transforming growth factor beta-1 (TGF- $\beta 1$ ) which accompany reductions in albuminuria indicates that GLP-1 receptor activation using exogenous agents is capable of influencing key molecular pathogenic mediators and markers of progressive DKD [79].

Further prospective studies are underway to add to the evidence base in relation to GLP-1 based pharmacotherapy and its effects on DKD. Patients with microalbuminuric DKD and CKD3 are being included in a 52-week study examining the effect of low-dose liraglutide on urinary albumin excretion and markers of renal inflammation (NCT01847313). Elsewhere a study focusing on DPP-IV inhibition using sitagliptin in patients with microalbuminuria and CKD stages $3-5$ is recruiting and will examine changes in urinary albumin excretion at 6 months (NCT01394341). The MARLINA study (NCT01792518) will focus in a phase IIIb trial setting on evaluating the effect of linagliptin ( $5 \mathrm{mg} /$ day) on changes in ACRs 
after 24 weeks of treatment. CARMELINA (NCT01897532) will conduct a 48-month phase IV double-blind RCT of linagliptin ( $5 \mathrm{mg} /$ day) looking at time to the first event in a composite renal end-point composed of renal death, endstage renal disease, and a sustained decrease of $50 \%$ or more in eGFR. Finally, CAROLINA (NCT01243424) is an ongoing double-blinded RCT examining the cardiovascular safety of linagliptin over an 8-year period which will incorporate examination of changes from baseline in albuminuria, serum creatinine, and eGFR.

\section{Summary and Perspectives}

Surgical approaches to the treatment of DKD point towards the potential role of GLP-1 as an important molecular mediator of risk factor reduction. The extent to which exogenous GLP-1 or pharmacological means of optimising endogenous GLP-1 levels may mimic the renoprotective effects of RYGB remains to be established. Indeed the renoprotective effects of RYGB versus medical therapy or other surgical modalities remain to be tested in prospective RCTs.

Nonetheless GLP-1 represents an attractive molecule to shed a light on in relation to the treatment of DKD given its pleiotropic effects on risk factors and promising results in preclinical rodent models. The extent however to which pharmacological mimicry of the GLP-1 dependent effects of surgery can be recapitulated by GLP-1 based therapy remains to be defined as it may be the case that some GLP-1 signalling events which are delivered via vagal afferents in the gut wall are important in long-term risk factor reduction after RYGB and may not be accurately replicated solely endocrine mediated pathways activated by exogenous GLP-1.

One potential means of preserving local gut wall signalling effects of GLP-1 in a nonsurgical setting is via the use of endoscopically delivered gastrointestinal liner devices that mimic proximal small intestinal bypass component of RYGB. The duodenal jejunal bypass liner modestly increases GLP-1 release and is efficacious with regard to weight loss and glycaemic control over a 1-2-year period [80, 81]. Studies of the effect of these devices on DKD risk factors and renal outcomes when included as a temporary initial component of optimisation during multimodal treatment regimens are mandated. Other potential avenues of interest in optimising endogenous GLP-1 release include the investigation of functional foods that could optimise postprandial GLP-1 release by acting as L-cell secretagogues.

From a mechanistic perspective in relation to the role of GLP-1 as a mediator of risk factor reduction after RYGB in patients, studies are mandated that will use exendins 939 in crossover design studies to examine the effect of acute inhibition of GLP-1 release in the postprandial period in RYGB patients. This will clarify whether GLP-1 has a similar effect on natriuretic responses as to those observed in relation to measures of hunger and fullness which are acutely ablated by antagonism of the GLP-1 receptor or suppression of gut hormone release. Such studies would be complimented by further work in vivo in animal models of DKD conducted in the GLP-1 receptor knockout mouse.

\section{Conflict of Interests}

The authors declare that there is no conflict of interests regarding the publishing of this paper.

\section{References}

[1] M. Afkarian, M. C. Sachs, B. Kestenbaum et al., "Kidney disease and increased mortality risk in type 2 diabetes," Journal of the American Society of Nephrology, vol. 24, no. 2, pp. 302-308, 2013.

[2] R. Li, P. Zhang, L. E. Barker, F. M. Chowdhury, and X. Zhang, "Cost-effectiveness of interventions to prevent and control diabetes mellitus: a systematic review," Diabetes Care, vol. 33, no. 8, pp. 1872-1894, 2010.

[3] A. I. Adler, R. J. Stevens, S. E. Manley, R. W. Bilous, C. A. Cull, and R. R. Holman, "Development and progression of nephropathy in type 2 diabetes: the United Kingdom Prospective Diabetes Study (UKPDS 64)," Kidney International, vol. 63, no. 1, pp. 225-232, 2003.

[4] S. G. Coca, F. Ismail-Beigi, N. Haq, H. M. Krumholz, and C. R. Parikh, "Role of intensive glucose control in development of renal end points in type 2 diabetes mellitus: systematic review and meta-analysis," Archives of Internal Medicine, vol. 172, no. 10, pp. 761-769, 2012.

[5] R. J. Macisaac, E. I. Ekinci, and G. Jerums, "Markers of and risk factors for the development and progression of diabetic kidney disease," American Journal of Kidney Diseases, vol. 63, pp. S39S62, 2014.

[6] UK Prospective Diabetes Study (UKPDS) Group, "Intensive blood-glucose control with sulphonylureas or insulin compared with conventional treatment and risk of complications in patients with type 2 diabetes (UKPDS 33)," The Lancet, vol. 352, no. 9131, pp. 837-853, 1998.

[7] R. R. Holman, S. K. Paul, M. A. Bethel, D. R. Matthews, and H. A. W. Neil, "10-Year follow-up of intensive glucose control in type 2 diabetes," New England Journal of Medicine, vol. 359, no. 15, pp. 1577-1589, 2008.

[8] P. Ruggenenti, P. Cravedi, and G. Remuzzi, "The RAAS in the pathogenesis and treatment of diabetic nephropathy," Nature Reviews: Nephrology, vol. 6, no. 6, pp. 319-330, 2010.

[9] B. E. de Galan, V. Perkovic, T. Ninomiya et al., "Lowering blood pressure reduces renal events in type 2 diabetes," Journal of the American Society of Nephrology, vol. 20, no. 4, pp. 883-892, 2009.

[10] B. M. Brenner, M. E. Cooper, D. De Zeeuw et al., "Effects of losartan on renal and cardiovascular outcomes in patients with type 2 diabetes and nephropathy," The New England Journal of Medicine, vol. 345, no. 12, pp. 861-869, 2001.

[11] P. Gæde, H. Lund-Andersen, H.-H. Parving, and O. Pedersen, "Effect of a multifactorial intervention on mortality in type 2 diabetes," New England Journal of Medicine, vol. 358, no. 6, pp. 580-591, 2008

[12] S. A. Brethauer, A. Aminian, H. Romero-Talamas et al., "Can diabetes be surgically cured? Long-term metabolic effects of bariatric surgery in obese patients with type 2 diabetes mellitus," Annals of Surgery, vol. 258, pp. 628-637, 2013.

[13] H. Buchwald, R. Estok, K. Fahrbach et al., "Weight and type 2 diabetes after bariatric surgery: systematic review and metaanalysis," The American Journal of Medicine, vol. 122, no. 3, pp. 248.e5-256.e5, 2009.

[14] L. Sjöström, A.-K. Lindroos, M. Peltonen et al., "Lifestyle, diabetes, and cardiovascular risk factors 10 years after bariatric 
surgery," The New England Journal of Medicine, vol. 351, no. 26, pp. 2683-2693, 2004.

[15] L. Sjöström, K. Narbro, C. D. Sjöström et al., "Effects of bariatric surgery on mortality in Swedish obese subjects," The New England Journal of Medicine, vol. 357, no. 8, pp. 741-752, 2007.

[16] K. J. Neff, A. H. Frankel, F. W. Tam, D. M. Sadlier, C. Godson, and C. W. le Roux, "The effect of bariatric surgery on renal function and disease: a focus on outcomes and inflammation," Nephrology Dialysis Transplantation, vol. 28, supplement 4, pp. 73-82, 2013.

[17] A. Iaconelli, S. Panunzi, A. de Gaetano et al., "Effects of bilio-pancreatic diversion on diabetic complications: a 10-year follow-up," Diabetes Care, vol. 34, no. 3, pp. 561-567, 2011.

[18] M. Navarro-Díaz, A. Serra, R. Romero et al., "Effect of drastic weight loss after bariatric surgery on renal parameters in extremely obese patients: long-term follow-up," Journal of the American Society of Nephrology, vol. 17, supplement 3, pp. S213S217, 2006.

[19] A. Amor, A. Jiménez, V. Moizé et al., "Weight loss independently predicts urinary albumin excretion normalization in morbidly obese type 2 diabetic patients undergoing bariatric surgery," Surgical Endoscopy, vol. 27, no. 6, pp. 2046-2051, 2013.

[20] W. K. Fenske, S. Dubb, M. Bueter et al., "Effect of bariatric surgery-induced weight loss on renal and systemic inflammation and blood pressure: a 12-month prospective study," Surgery for Obesity and Related Diseases, vol. 9, no. 4, pp. 559-568, 2013.

[21] B. L. Johnson, D. W. Blackhurst, B. B. Latham et al., "Bariatric surgery is associated with a reduction in major macrovascular and microvascular complications in moderately to severely obese patients with type 2 diabetes mellitus," Journal of the American College of Surgeons, vol. 216, no. 4, pp. 545-558, 2013.

[22] A. D. Miras, L. L. Chuah, G. Lascaratos et al., "Bariatric surgery does not exacerbate and may be beneficial for the microvascular complications of type 2 diabetes," Diabetes Care, vol. 35, no. 12, article e81, 2012.

[23] H. M. Heneghan, D. Cetin, S. D. Navaneethan, N. Orzech, S. A. Brethauer, and P. R. Schauer, "Effects of bariatric surgery on diabetic nephropathy after 5 years of follow-up," Surgery for Obesity and Related Diseases, vol. 9, no. 1, pp. 7-14, 2013.

[24] L. M. Carlsson, S. Romeo, P. Jacobson et al., "The incidence of albuminuria after bariatric surgery and usual care in swedish obese subjects (SOS): a prospective controlled intervention trial," International journal of obesity, 2014.

[25] D. T. Stephenson, K. Jandeleit-Dahm, B. Balkau, and N. Cohen, "Improvement in albuminuria in patients with type 2 diabetes after laparoscopic adjustable gastric banding," Diabetes \& Vascular Disease Research, vol. 10, pp. 514-519, 2013.

[26] B. Jose, S. Ford, P. Super, G. N. Thomas, I. Dasgupta, and S. Taheri, "The effect of biliopancreatic diversion surgery on renal function: a retrospective study," Obesity Surgery, vol. 23, no. 5, pp. 634-637, 2013.

[27] C.-C. Hou, R.-S. Shyu, W.-J. Lee, K.-H. Ser, Y.-C. Lee, and S.C. Chen, "Improved renal function 12 months after bariatric surgery," Surgery for Obesity and Related Diseases, vol. 9, no. 2, pp. 202-206, 2013.

[28] J. M. Cloyd, Y. Ma, J. M. Morton, M. K. Tamura, G. A. Poultsides, and B. C. Visser, "Does chronic kidney disease affect outcomes after major abdominal surgery? Results from the National surgical quality improvement program," Journal of Gastrointestinal Surgery, vol. 18, no. 3, pp. 605-612, 2014.

[29] M. K. Sinha, M. L. Collazo-Clavell, A. Rule et al., "Hyperoxaluric nephrolithiasis is a complication of Roux-en-Y gastric bypass surgery," Kidney International, vol. 72, no. 1, pp. 100-107, 2007.

[30] H. Buchwald, Y. Avidor, E. Braunwald et al., "Bariatric surgery: a systematic review and meta-analysis," The Journal of the American Medical Association, vol. 292, no. 14, pp. 1724-1737, 2004.

[31] W. J. Pories, M. S. Swanson, K. G. MacDonald et al., "Who would have thought it? An operation proves to be the most effective therapy for adult-onset diabetes mellitus," Annals of Surgery, vol. 222, no. 3, pp. 339-352, 1995.

[32] G. Mingrone, S. Panunzi, A. De Gaetano et al., "Bariatric surgery versus conventional medical therapy for type 2 diabetes," The New England Journal of Medicine, vol. 366, no. 17, pp. 1577-1585, 2012.

[33] P. R. Schauer, S. R. Kashyap, K. Wolski et al., "Bariatric surgery versus intensive medical therapy in obese patients with diabetes," New England Journal of Medicine, vol. 366, no. 17, pp. 1567-1576, 2012.

[34] P. R. Schauer, D. L. Bhatt, J. P. Kirwan et al., "Bariatric surgery versus intensive medical therapy for diabetes - 3-year outcomes," The New England Journal of Medicine, vol. 370, pp. 2002-2013, 2014.

[35] L. M. S. Carlsson, M. Peltonen, S. Ahlin et al., "Bariatric surgery and prevention of type 2 diabetes in Swedish obese subjects," New England Journal of Medicine, vol. 367, no. 8, pp. 695-704, 2012.

[36] M. Castagneto and G. Mingrone, "The effect of gastrointestinal surgery on insulin resistance and insulin secretion," Current Atherosclerosis Reports, vol. 14, no. 6, pp. 624-630, 2012.

[37] C. Dirksen, N. B. Jørgensen, K. N. Bojsen-Møller et al., "Mechanisms of improved glycaemic control after Roux-en-Y gastric bypass," Diabetologia, vol. 55, no. 7, pp. 1890-1901, 2012.

[38] C. Maric and J. E. Hall, "Obesity, Metabolic syndrome and diabetic nephropathy," Contributions to Nephrology, vol. 170, pp. 28-35, 2011.

[39] P. Hallersund, L. Sjöström, T. Olbers et al., "Gastric bypass surgery is followed by lowered blood pressure and increased diuresis: long term results from the Swedish Obese Subjects (SOS) study," PLoS ONE, vol. 7, no. 11, Article ID e49696, 2012.

[40] D. Hofsø, N. Nordstrand, L. K. Johnson et al., “Obesityrelated cardiovascular risk factors after weight loss: a clinical trial comparing gastric bypass surgery and intensive lifestyle intervention," European Journal of Endocrinology, vol. 163, no. 5, pp. 735-745, 2010.

[41] C. Martins, M. Strømmen, O. A. Stavne, R. Nossum, R. Mårvik, and B. Kulseng, "Bariatric surgery versus lifestyle interventions for morbid obesity-changes in body weight, risk factors and comorbidities at 1 year," Obesity Surgery, vol. 21, no. 7, pp. 841849, 2011.

[42] Z. Liang, Q. Wu, B. Chen, P. Yu, H. Zhao, and X. Ouyang, "Effect of laparoscopic Roux-en-Y gastric bypass surgery on type 2 diabetes mellitus with hypertension: a randomized controlled trial," Diabetes Research and Clinical Practice, vol. 101, no. 1, pp. 50-56, 2013.

[43] S. Ikramuddin, J. Korner, W.-J. Lee et al., "Roux-en-Y gastric bypass vs intensive medical management for the control of type 2 diabetes, hypertension, and hyperlipidemia: the diabetes surgery study randomized clinical trial," The Journal of the American Medical Association, vol. 309, no. 21, pp. 2240-2249, 2013. 
[44] A. R. Ahmed, G. Rickards, D. Coniglio et al., "Laparoscopic Roux-en-Y gastric bypass and its early effect on blood pressure," Obesity Surgery, vol. 19, no. 7, pp. 845-849, 2009.

[45] M. W. Hinojosa, J. E. Varela, B. R. Smith, F. Che, and N. T. Nguyen, "Resolution of systemic hypertension after laparoscopic gastric bypass," Journal of Gastrointestinal Surgery, vol. 13, no. 4, pp. 793-797, 2009.

[46] J. E. Campbell and D. J. Drucker, "Pharmacology, physiology, and mechanisms of incretin hormone action," Cell Metabolism, vol. 17, no. 6, pp. 819-837, 2013.

[47] D. S. Shyangdan, P. Royle, C. Clar, P. Sharma, N. Waugh, and A. Snaith, "Glucagon-like peptide analogues for type 2 diabetes mellitus," Cochrane Database of Systematic Reviews, vol. 5, no. 10, Article ID CD006423, 2011.

[48] A. Astrup, R. Carraro, N. Finer et al., "Safety, tolerability and sustained weight loss over 2 years with the once-daily human GLP-1 analog, liraglutide," International Journal of Obesity, vol. 36, no. 6, pp. 843-854, 2012.

[49] A. Astrup, S. Rössner, L. van Gaal et al., "Effects of liraglutide in the treatment of obesity: a randomised, double-blind, placebocontrolled study," The Lancet, vol. 374, no. 9701, pp. 1606-1616, 2009.

[50] T. A. Wadden, P. Hollander, S. Klein et al., "Weight maintenance and additional weight loss with liraglutide after low-caloriediet-induced weight loss: the Scale Maintenance randomized study," International Journal of Obesity, vol. 37, pp. 1443-1451, 2013.

[51] V. A. Fonseca, J. H. Devries, R. R. Henry, M. Donsmark, H. F. Thomsen, and J. Plutzky, "Reductions in systolic blood pressure with liraglutide in patients with type 2 diabetes: Insights from a patient-level pooled analysis of six randomized clinical trials," Journal of Diabetes and Its Complications, vol. 28, no. 3, pp. 399405, 2014.

[52] M. Shah, J. H. Law, F. Micheletto et al., "Contribution of endogenous glucagon-like peptide 1 to glucose metabolism after Roux-en-Y gastric bypass," Diabetes, vol. 63, pp. 483-493, 2014.

[53] A. Jiménez, R. Casamitjana, L. Flores, S. Delgado, A. Lacy, and J. Vidal, "GLP-1 and the long-term outcome of type 2 diabetes mellitus after Roux-en-Y gastric bypass surgery in morbidly obese subjects," Annals of Surgery, vol. 257, no. 5, pp. 894-899, 2013.

[54] J. Korner, M. Bessler, W. Inabnet, C. Taveras, and J. J. Holst, "Exaggerated glucagon-like peptide-1 and blunted glucosedependent insulinotropic peptide secretion are associated with Roux-en-Y gastric bypass but not adjustable gastric banding," Surgery for Obesity and Related Diseases, vol. 3, no. 6, pp. 597601, 2007.

[55] A. P. Courcoulas, N. J. Christian, S. H. Belle et al., "Weight change and health outcomes at 3 years after bariatric surgery among individuals with severe obesity," Journal of the American Medical Association, vol. 310, pp. 2416-2425, 2013.

[56] M. Bueter, H. Ashrafian, A. H. Frankel, F. W. K. Tam, R. J. Unwin, and C. W. Le Roux, "Sodium and water handling after gastric bypass surgery in a rat model," Surgery for Obesity and Related Diseases, vol. 7, no. 1, pp. 68-73, 2011.

[57] A. Jiménez, R. Casamitjana, L. Flores et al., "Long-term effects of sleeve gastrectomy and roux-en-y gastric bypass surgery on type 2 diabetes mellitus in morbidly obese subjects," Annals of Surgery, vol. 256, no. 6, pp. 1023-1029, 2012.
[58] J.-P. Gutzwiller, S. Tschopp, A. Bock et al., "Glucagon-like peptide 1 induces natriuresis in healthy subjects and in insulinresistant obese men," The Journal of Clinical Endocrinology and Metabolism, vol. 89, no. 6, pp. 3055-3061, 2004.

[59] R. O. Crajoinas, F. T. Oricchio, T. D. Pessoa et al., "Mechanisms mediating the diuretic and natriuretic actions of the incretin hormone glucagon-like peptide-1," The American Journal of Physiology, vol. 301, no. 2, pp. F355-F363, 2011.

[60] T. Rieg, M. Gerasimova, F. Murray et al., "Natriuretic effect by exendin-4, but not the DPP-4 inhibitor alogliptin, is mediated via the GLP-1 receptor and preserved in obese type 2 diabetic mice," The American Journal of Physiology-Renal Physiology, vol. 303, no. 7, pp. F963-F971, 2012.

[61] E. Jensen, "Activation of renal GLP-1 receptors located in the afferent arteriole causes an increase in renal blood flow," Diabetologia, vol. 56, p. 255, 2013.

[62] S. C. Thomson, A. Kashkouli, and P. Singh, "Glucagon-like peptide-1 receptor stimulation increases GFR and suppresses proximal reabsorption in the rat," American Journal of Physiology: Renal Physiology, vol. 304, no. 2, pp. F137-F144, 2013.

[63] M. Kim, M. J. Platt, T. Shibasaki et al., "GLP-1 receptor activation and Epac2 link atrial natriuretic peptide secretion to control of blood pressure," Nature Medicine, vol. 19, no. 5, pp. 567-575, 2013.

[64] N. Abrahamsson, B. E. Engström, M. Sundbom, and F. A. Karlsson, "Gastric bypass surgery elevates NT-ProBNP levels," Obesity Surgery, vol. 23, no. 9, pp. 1421-1426, 2013.

[65] J. Klisic, M. C. Hu, V. Nief et al., "Insulin activates $\mathrm{Na}+\mathrm{H}+$ exchanger 3: biphasic response and glucocorticoid dependence," The American Journal of Physiology-Renal Physiology, vol. 283, no. 3, pp. F532-F539, 2002.

[66] H. Fujita, T. Morii, H. Fujishima et al., "The protective roles of GLP-1R signaling in diabetic nephropathy: possible mechanism and therapeutic potential," Kidney International, vol. 85, pp. 579-589, 2014.

[67] H. Hendarto, T. Inoguchi, Y. Maeda et al., "GLP-1 analog liraglutide protects against oxidative stress and albuminuria in streptozotocin-induced diabetic rats via protein kinase Amediated inhibition of renal $\mathrm{NAD}(\mathrm{P}) \mathrm{H}$ oxidases," Metabolism: Clinical and Experimental, vol. 61, no. 10, pp. 1422-1434, 2012.

[68] A. Ojima, Y. Ishibashi, T. Matsui et al., "Glucagon-like peptide1 receptor agonist inhibits asymmetric dimethylarginine generation in the kidney of streptozotocin-induced diabetic rats by blocking advanced glycation end product-induced protein arginine methyltranferase-1 expression," The American Journal of Pathology, vol. 182, no. 1, pp. 132-141, 2013.

[69] R. Kodera, K. Shikata, H. U. Kataoka et al., "Glucagon-like peptide-1 receptor agonist ameliorates renal injury through its anti-inflammatory action without lowering blood glucose level in a rat model of type 1 diabetes," Diabetologia, vol. 54, no. 4, pp. 965-978, 2011.

[70] C. W. Park, H. W. Kim, S. H. Ko et al., "Long-term treatment of glucagon-like peptide-1 analog exendin-4 ameliorates diabetic nephropathy through improving metabolic anomalies in $\mathrm{db} / \mathrm{db}$ mice," Journal of the American Society of Nephrology, vol. 18, no. 4, pp. 1227-1238, 2007.

[71] W. J. Liu, S. H. Xie, Y. N. Liu et al., "Dipeptidyl peptidase IV inhibitor attenuates kidney injury in streptozotocin-induced diabetic rats," Journal of Pharmacology and Experimental Therapeutics, vol. 340, no. 2, pp. 248-255, 2012. 
[72] R. Kodera, K. Shikata, T. Takatsuka et al., "Dipeptidyl peptidase4 inhibitor ameliorates early renal injury through its antiinflammatory action in a rat model of type 1 diabetes," Biochemical and Biophysical Research Communications, vol. 443, pp. 828833, 2014.

[73] M. L. Alter, I. M. Ott, K. von Websky et al., "DPP-4 inhibition on top of angiotensin receptor blockade offers a new therapeutic approach for diabetic nephropathy," Kidney \& Blood Pressure Research, vol. 36, no. 1, pp. 119-130, 2012.

[74] C. Mega, E. T. de Lemos, H. Vala et al., "Diabetic nephropathy amelioration by a low-dose sitagliptin in an animal model of type 2 diabetes (Zucker diabetic fatty rat)," Experimental Diabetes Research, vol. 2011, Article ID 162092, 12 pages, 2011.

[75] Y. Wang, S. Landheer, W. H. van Gilst et al., "Attenuation of renovascular damage in Zucker diabetic fatty rat by NWT-03, an egg protein hydrolysate with ACE- and DPP4-inhibitory activity," PLoS ONE, vol. 7, no. 10, Article ID e46781, 2012.

[76] I. Kawasaki, Y. Hiura, A. Tamai et al., "Sitagliptin reduces the urine albumin-to-creatinine ratio in type 2 diabetes through decreasing both blood pressure and estimated glomerular filtration rate," Journal of Diabetes, 2014.

[77] P. H. Groop, M. E. Cooper, V. Perkovic, A. Emser, H. J. Woerle, and M. von Eynatten, "Linagliptin lowers albuminuria on top of recommended standard treatment in patients with type 2 diabetes and renal dysfunction," Diabetes Care, vol. 36, pp. 3460-3468, 2013.

[78] S. Imamura, K. Hirai, and A. Hirai, "The glucagon-like peptide-1 receptor agonist, liraglutide, attenuates the progression of overt diabetic nephropathy in type 2 diabetic patients," The Tohoku Journal of Experimental Medicine, vol. 231, pp. 57-61, 2013.

[79] L. Varadhan, T. Humphreys, A. B. Walker, C. V. N. Cheruvu, and G. I. Varughese, "Bariatric surgery and diabetic retinopathy: a pilot analysis," Obesity Surgery, vol. 22, no. 3, pp. 515-516, 2012.

[80] R. Cohen, C. W. Le Roux, D. Papamargaritis et al., "Role of proximal gut exclusion from food on glucose homeostasis in patients with Type 2 diabetes," Diabetic Medicine, vol. 30, no. 12, pp. 1482-1486, 2013.

[81] C. de Jonge, S. S. Rensen, F. J. Verdam et al., "Endoscopic duodenal-jejunal bypass liner rapidly improves type 2 diabetes," Obesity Surgery, vol. 23, no. 9, pp. 1354-1360, 2013. 


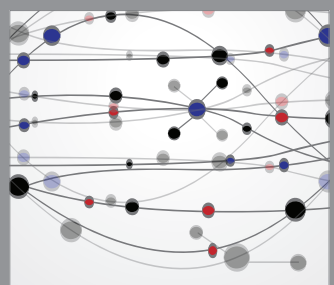

The Scientific World Journal
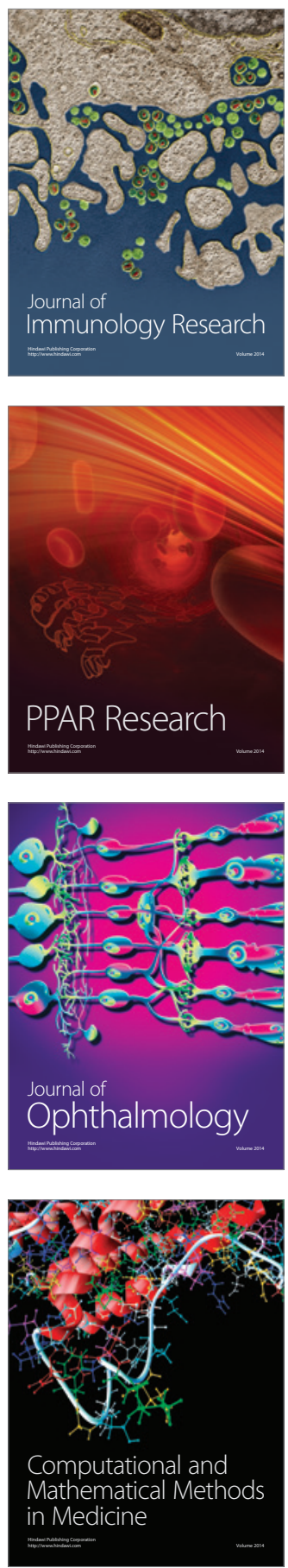

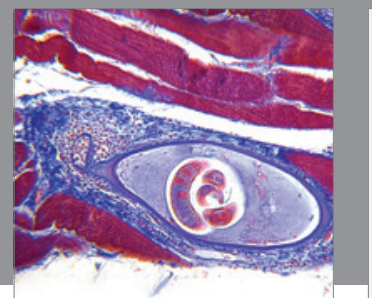

Gastroenterology

Research and Practice
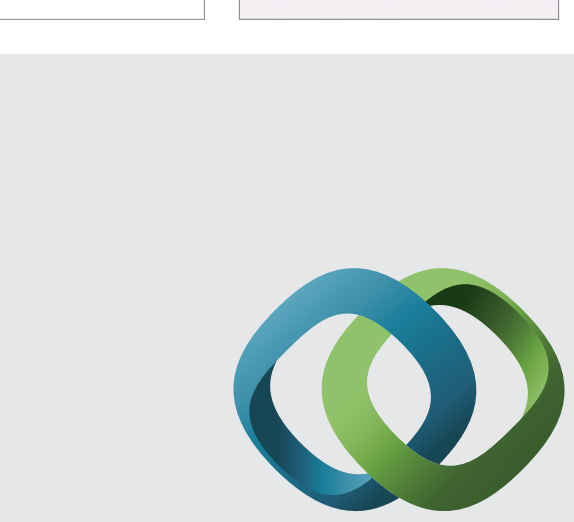

\section{Hindawi}

Submit your manuscripts at

http://www.hindawi.com
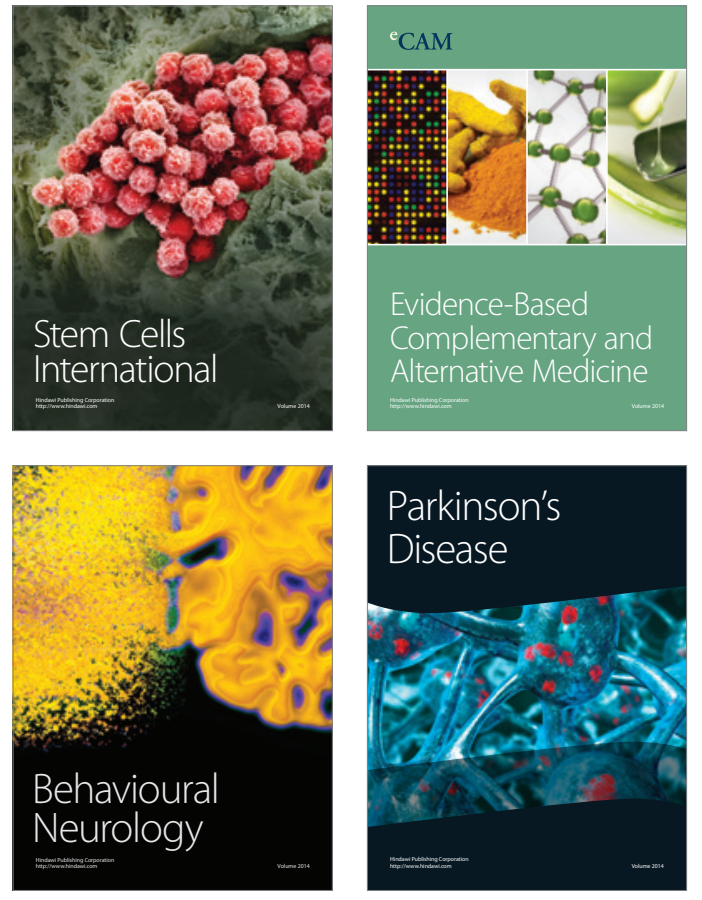
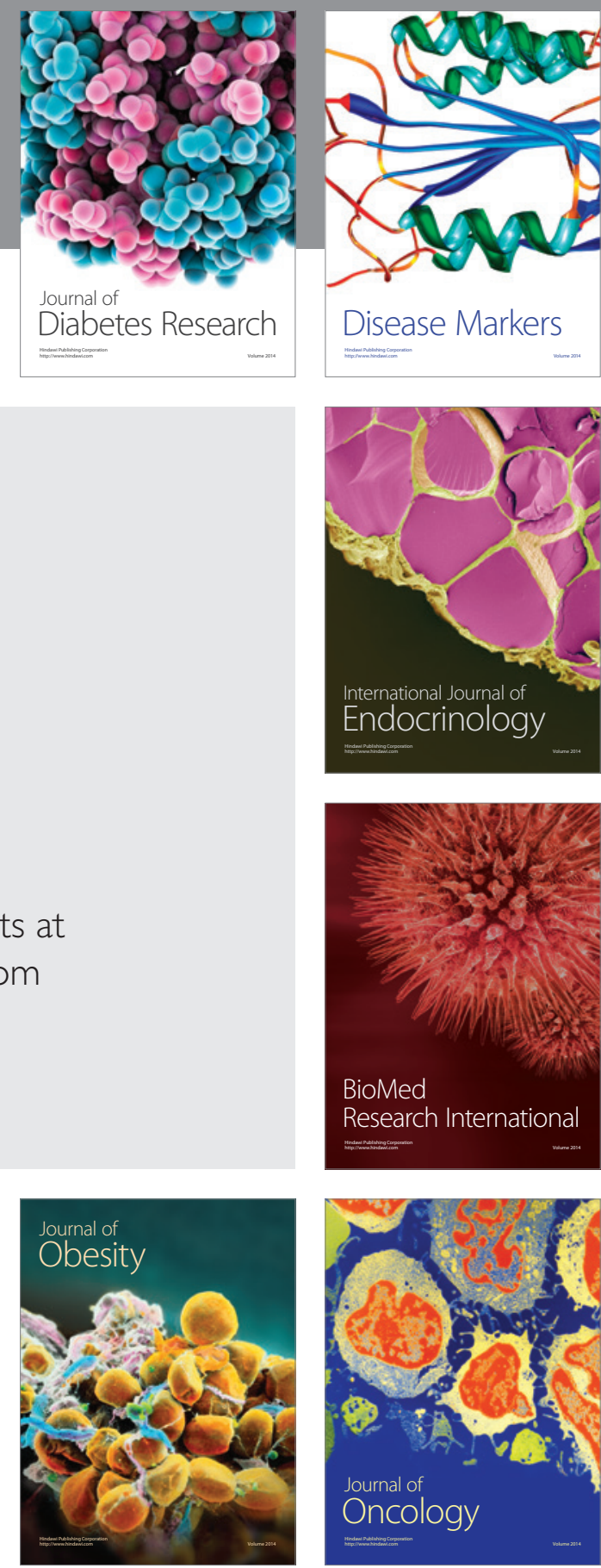

Disease Markers
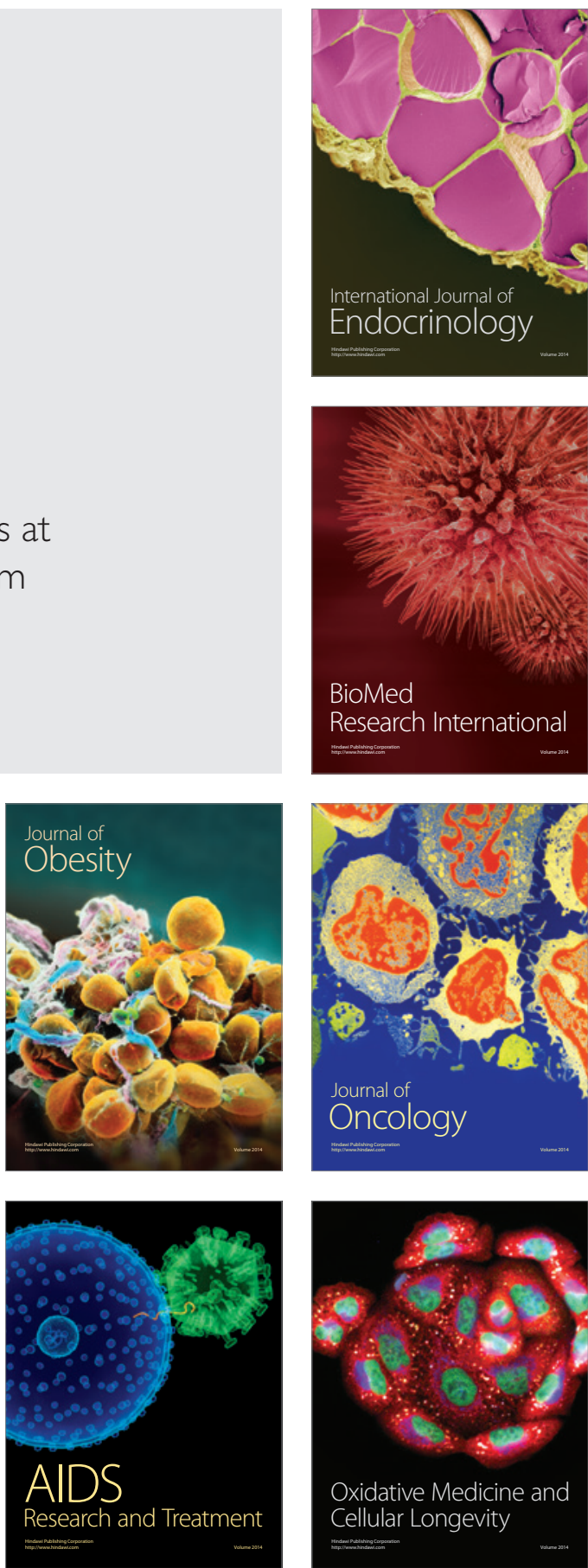